\title{
Desenvolvimento de podcasts na perspectiva BYOD em aulas de língua inglesa
}

Fábio Correia de Rezende - IME/UFBA - fabiocr@ufba.br

Ecivaldo de Souza Matos - IME/UFBA - ecivaldo@ufba.br

Resumo: Este relato apresenta uma experiência educativa com o uso e a produção de podcast por meio da abordagem conhecida por Bring Your Own Device por estudantes do ensino médio de escola pública de Salvador. As ações pedagógicas contemplaram o uso dos smartphones dos sujeitos envolvidos (professor e estudantes) para ensino de simple past - regular verbs. Destaca-se no embasamento teórico o conceito de podcast, raciocínio computacional - habilidades e BYOD. Os resultados apontam o potencial de uso dos aparelhos dos estudantes como elemento motivador em sala de aula, proporcionando dedicação dos estudantes e suporte ao aprendizado.

Palavras-chave: podcast, BYOD, língua inglesa, mobile learning, educação básica.

\section{Development of podcasts in the BYOD perspective in English language classes}

Abstract: This paper presents an educative experience with use and production of podcasts with the Bring Your Own Device approach by high school students of a public school of Salvador. In this perspective, the teacher and the students used their own smartphones to study simple past of English regular verbs. It stands out basement theoretical framework concept of podcast, computational thinking - skills and BYOD. The results point out the potential of using students' devices as a motivating element in classroom, providing student dedication and learning support.

Keywords: podcast, BYOD, english language, mobile learning, basic education.

\section{Introdução}

Os dispositivos móveis, como tablets, smartphones e laptops/notebooks, têm marcado presença no cotidiano dos jovens em idade escolar. Segundo Figueiredo (2011), isso reflete no aumento do número de estudantes com acesso a mecanismos de aprendizagem e entretenimento móvel.

Segundo a Insight (2011), o Brasil atingiu $142 \%$ de aumento no uso de dispositivos móveis e consequentemente, isso tem proporcionado o uso dos equipamentos com finalidades educativas. Cerca de $38 \%$ dos brasileiros que navegam pela internet utilizam um dispositivo móvel e mais de 8 milhões de brasileiros usaram exclusivamente, os dispositivos móveis para acessar a internet (Insight, 2011).

Devido ao aumento do número de estudantes com acesso à tecnologia móvel, Silva et al. (2012) propuseram o uso e a produção de podcast como uma alternativa para os professores nas aulas de língua inglesa desenvolverem as habilidades de listening e speaking (ouvir e falar - tradução livre) e o desenvolvimento dessas habilidades, também coopera com o desenvolvimento de competências de língua estrangeira moderna, por exemplo, a competência "Ler e interpretar textos de diversas naturezas" (PCN+, 2002, p.127).

Podcast é "um processo midiático que emerge a partir da publicação de arquivos de áudio na Internet” (PRIMO, 2005, p. 01). Para Botton, Peripolli e Santos (2017), podcast pode ser empregado na educação por diversas formas e é "um arquivo de áudio 
(...) podendo ser produzido pelo próprio usuário de forma informal ou profissional" (BOTTON, PERIPOLLI, SANTOS, 2017, p. 01).

De acordo com Dos Reis (2014), a habilidade oral (speaking) necessita ser melhor desenvolvida nas escolas públicas. Silva (2011) destaca três causas complicadoras para inserção do speaking nas escolas: o preconceito por parte dos professores, devido a ausência de equipamentos didáticos adequados no ambiente escolar; a falta de equipamentos tecnológicos na escola; e a ausência de um contexto social para o aluno praticar a oralidade da língua inglesa.

Nesse sentido, Silva (2011) destaca o "podcast como uma possível aliada ao desenvolvimento da oralidade, sem exigir alto nível de letramento digital por parte de seus usuários" (Silva, 2011, p. 03). Produzir podcasts, segundo Phillips (2015; 2017), exige que os estudantes se dediquem e desenvolvam habilidades, como pesquisar e analisar informações, elaborar um roteiro sistematizado e realizar gravações, em função da melhoria da pronúncia e consequentemente da fluência em língua inglesa.

A utilização de podcasts pode contribuir ao ensino e aprendizagem, "uma vez que esse recurso privilegia o trabalho com a pronúncia, a acentuação e a inflexão, contemplando diretamente as habilidades de listening e speaking" (Dutra, 2016, p. 246). O podcast em sala de aula pode ser subsidiado por meio da abordagem Bring Your Own Device (BYOD) ("traga seu próprio aparelho", tradução nossa).

De acordo com Shuler (2013), o BYOD está fortemente relacionado ao mobile learning (m-learning) e inclui diferentes tipos de dispositivos portáteis sem fio como smartphones, tablets e consoles de videogame. Para Prensky (2011), as características da mobilidade ampliaram-se para os usuários em função da própria aprendizagem.

Este artigo apresenta uma experiência educativa realizada com o uso e a produção de podcast para favorecimento da aprendizagem de conteúdos de língua inglesa, cujas atividades contemplaram o uso dos aparelhos dos estudantes como elemento motivador em sala de aula.

Este texto está estruturado da seguinte forma: na segunda seção apresentamos embasamento teórico sobre podcast, BYOD e raciocínio computacional; a terceira seção expõe a metodologia de intervenção; na quarta seção detalhamos a produção dos podcasts; seguida dos resultados e conclusões nas duas últimas seções, respectivamente.

\section{Embasamento Teórico}

Aarreniemi-Jokipelto e Goulart (2017) mostraram como os dispositivos móveis no contexto do mobile learning podem oferecer uma oportunidade de aprendizagem a comunidades e países, onde outras formas de ensino não são viáveis, devido aos fatores financeiros, geográficos apoiados no podcast e a abordagem BYOD.

$\mathrm{O}$ mobile learning "pode proporcionar aos estudantes o senso de liberdade para estudar em qualquer lugar e a qualquer momento através de conteúdos multimídia (como áudios, imagens e vídeos), que estão associados ao aspecto lúdico da aprendizagem" (Marçal et al. 2016, p. 3). Barcelos, Tarouco e Bercht (2009, p. 5) afirmam que o "Mobile Learning é utilizado para denotar ensino através de aparelhos móveis ou dispositivos móveis, possíveis pelos avanços na tecnologia na área da informática".

Um podcast é "um arquivo de áudio digital (ou vídeo) criado e carregado em uma plataforma online para compartilhar com outros plataformas, o podcast também é parte do paradigma da Aprendizagem de Línguas Assistida por Dispositivos Móveis do inglês "(Mobile Assisted Language Learning - MALL)" (Phillips, 2017, 159). 
Bottentuir Junior e Coutinho (2007), apresentam algumas vantagens para o professor utilizar o podcast na escola: os textos, as imagens, os áudio e hipertexto em sua maioria são compatíveis com os aparelhos celulares; o aluno não necessita ter conhecimentos aprofundados em informática; os podcasts podem ser reproduzidos de forma individual ou coletiva; e, de forma geral, os conteúdos em formato digital é de acesso livre.

O Ministério da Educação do Canadá desenvolveu um guia para as escolas chamado Bring Your Own Device: A Guide for Schools. Esse guia surgiu devido à presença da telefonia móvel nos ambientes escolares. O guia fornece informações sobre como a comunidade escolar pode proceder sobre o uso da abordagem BYOD dentro do ambiente escolar (Alberta, 2012).

Costa et al. (2016) realizaram um trabalho que viabilizou o uso de aparelhos celulares em função da educação dos estudantes e para melhoria das práticas didáticas e pedagógicas dos professores. Xavier e Dias (2012), por sua vez, descrevem as práticas pedagógicas com o aparelho celular nas aulas de inglês a partir dos princípios do paradigma da Aprendizagem de Línguas Assistida por Dispositivos Móveis.

Tendo em vista os conceitos do mobile learning, BYOD e podcast a partir dos autores citados, este trabalho aborda o pensamento computacional ou raciocínio computacional e as suas habilidades oriundas da Ciência da Computação.

Assim, o Raciocínio Computacional (RC), do inglês Computational Thinking, para Wing (2006), o RC é um conjunto de habilidades lógico-operacionais de raciocínio fundamentadas na Ciência da Computação. Ainda, complementa que é uma nova metodologia para resolução de problemas a partir da combinação do pensamento crítico com fundamentos da Ciência da Computação.

$\mathrm{O}$ RC pode ser considerado como um agrupamento de habilidades ou processos cognitivos. Dentre as diversas habilidades compositoras do RC, destacam-se abstração e reconhecimento de padrões. A abstração, segundo Csizmadia (2015),

\footnotetext{
é um processo de tornar um artefato mais compreensível, reduzindo os detalhes desnecessários, é escolher e esconder o detalhe certo para que o problema se torne mais fácil, sem perder nada que seja importante. Uma parte fundamental disso está na escolha de uma boa representação de um sistema. Representações diferentes facilitam coisas diferentes (Csizmadia, 2015, p. 07).
}

O "Reconhecimento de Padrões é o campo da ciência que tem por objetivo a classificação de objetos em um determinado número de categorias ou classes a partir da observação de suas características" (Theodoridis e Koutroumbas, 2009, p. 1). Assim, um padrão pode ser entendido como um conjunto de características semelhantes, no contexto, as regras do simple past da língua inglesa possuem um conjunto de características.

O Reconhecimento de Padrões pode ser entendido como um processo de resolução de novos problemas com base em soluções anteriores. Csizmadia (2015), ressalta que é importante no processo de desenvolvimento dessa habilidade, fazer perguntas como "Isso é semelhante a um problema que já resolvi? O que é igual e o que é diferente? Portanto, o reconhecimento de padrões é "perceber a similaridade, conexões e características de um determinado problema” (Csizmadia, 2015, p. 08).

\section{Metodologia}


A intervenção relatada neste artigo ocorreu em uma escola pública estadual de ensino médio sediada em Salvador. A escola funciona com as três séries do ensino médio, possui 27 salas de aula, 1500 alunos e 60 professores. Também há uma quadra poliesportiva, auditório para 300 pessoas, biblioteca e laboratório de química, física e biologia, mas sem laboratório de informática. Participaram dessa experiência 36 estudantes, todos com 16 anos de idade e uma professora. A professora é formada em Letras Vernáculas com habilitação em Língua Inglesa e leciona inglês desde 2003.

Para realização da intervenção, os estudantes levaram seus próprios aparelhos celulares e foi possível utilizar a internet banda larga de acesso à internet da escola. Para obter o sinal de internet, os estudantes foram deslocados da sala de aula para o auditório, com autorização prévia da direção e coordenação. O espaço e as acomodações eram adequados para a realização da atividade.

No auditório, os estudantes formaram equipes de até quatro integrantes. Cada equipe manteve-se a uma distância adequada de outra equipe, para que pudessem ouvir e produzir os podcasts sem interferências sonoras. O tempo planejado para essa ação foi de duas horas/aulas de 50 minutos cada, pois essas aulas estavam planejadas para ocorrerem após as explicações dos conteúdos planejados na aula de inglês.

A atividade com o podcast foi planejada conforme o conteúdo do livro didático ${ }^{1}$ adotado pela escola conforme o Programa Nacional do Livro Didático. Seguindo o planejamento, antes da atividade com o podcast ocorreram as aulas a partir da temática cantores de hip-hop sobre o conteúdo gênero biográfico e explicações o simple past regular verbs. Esses conteúdos foram desenvolvidos com o uso do celular, por meio da abordagem BYOD e de mapas conceituais, no entanto o foco deste relato é o uso e a produção de podcast. Após as ações relatadas, ocorreu a aula planejada para o uso e produção do podcast. Ao final da intervenção, a professora e oito estudantes participaram de uma entrevista individual, selecionados por voluntariado.

\section{Detalhamento da produção dos podcasts}

Primeiramente, a Figura 1 foi enviada no grupo de WhatsApp ${ }^{2}$ da turma. Assim, a professora leu os verbos em voz alta e em seguida, leu todos os verbos com os estudantes e (re)explicou porque são verbos regulares e as diferenças de sons.

\begin{tabular}{|c|c|c|c|}
\hline IIII & ly & IOI & \\
\hline accepted & asked & answered & \\
\hline collected & danced & changed & Caso você tonha \\
\hline decided & finished & died & $\begin{array}{l}\text { Caso vocétenha } \\
\text { dúvidas sobre a }\end{array}$ \\
\hline graduated & kissed & enjoyed & pronúncia de algum \\
\hline included & missed & happened & $\begin{array}{l}\text { verbo, consulte o gui } \\
\text { de pronúncia em um }\end{array}$ \\
\hline invented & $\begin{array}{l}\text { pronounced } \\
\text { relaxed }\end{array}$ & $\begin{array}{l}\text { lived } \\
\text { opened }\end{array}$ & dicionário de inglès. \\
\hline needed & $\begin{array}{l}\text { relaxed } \\
\text { stopped }\end{array}$ & saved & \\
\hline painted & $\begin{array}{l}\text { stopped } \\
\text { talked }\end{array}$ & shared & \\
\hline $\begin{array}{l}\text { presented } \\
\text { started }\end{array}$ & $\begin{array}{l}\text { talked } \\
\text { walked }\end{array}$ & studied & \\
\hline $\begin{array}{l}\text { started } \\
\text { visited }\end{array}$ & $\begin{array}{l}\text { walked } \\
\text { washed }\end{array}$ & tried & \\
\hline $\begin{array}{l}\text { visited } \\
\text { waited }\end{array}$ & watched & traveled & \\
\hline wanted & worked & used & \\
\hline
\end{tabular}

Figura 1 - Lista de Verbos Regulares - Simple Past (Fonte: DIAS, JUCÁ e FARIA, 2013, p.73).

Em seguida, por meio de uma mini caixa de som, os estudantes ouviram os verbos das três colunas e repetiram a pronúncia dos verbos. Em seguida, enviou-se o

\footnotetext{
1 Ainda que ocorreu o uso de tecnologias digitais, não nos privamos de utilizar o livro didático porque a professora o utiliza em todas as aulas de inglês pois essa ação está inserida no PPP da escola.

${ }^{2}$ WhatsApp é um aplicativo multiplataforma de mensagens instantâneas e chamadas de voz para smartphones.
} 
podcast dos verbos para o grupo de WhatsApp. O livro didático vem acompanhado com um CD de áudio, porém não é comum usá-lo em sala de aula, assim o podcast fez-se necessário e útil para os estudantes terem acesso ao áudio.

Após receberem e baixar o áudio, formaram-se equipes. Os estudantes puderam disponibilizar para os colegas o áudio através do bluetooth $^{3}$. Nem todos, sendo a minoria não conseguiram conectar seus aparelhos celulares a rede wi-fi.

Os aluno de posse do podcast e a lista de verbos, o próximo passo foi ouvir o áudio várias vezes. O podcast relaciona-se com os verbos terminados em /id/, /t/ e /d/, sendo que cada coluna representa um som, respectivamente. $\mathrm{O}$ objetivo foi compreender a regra gramatical, verbos terminados em -ed, se encontram no tempo passado. Aqui, ressalta-se o desenvolvimento das competências abstração e reconhecimento de padrões.

Os estudantes tiveram comportamentos diversos quando ouviram o podcast. Muitos consideravam engraçados e sorriam; outros se concentravam para ouvir as diferenças fonéticas; alguns usavam fones de ouvidos e outros ouviam em duplas dentro da equipe. O comportamento com risos e diversão durante a atividade foi compreensível pelo fato de eles não terem o hábito de praticar a habilidade de listening (escuta de áudios). A professora relatou que dificilmente utiliza algum tipo de áudio nas aulas de inglês porque a escola não possui equipamentos apropriados. Essa foi a primeira experiência com a abordagem BYOD e podcast.

Os estudantes deveriam produzir seus próprios podcast e enviá-los para o grupo de WhatsApp. Dentre as colunas na Figura 1, puderam escolher a coluna e os verbos para, em seguida, tentar a produção do podcast. A timidez para produzirem seus próprios podcasts foi outro detalhe observado. Alguns relataram vergonha para expor a voz no grupo de WhatsApp.

Alguns estudantes relataram que a vergonha de falar inglês está no fato de que os colegas poderiam rir ao ouvir os podcasts produzidos. Para esses estudantes que se sentiram envergonhados, solicitou-se o envio de suas produções para o WhatsApp da professora, em vez de enviarem para o grupo da turma. Contudo, a maioria dos podcasts produzidos foram enviados para o grupo. Dentre o total de estudantes presentes nessa atividade, 17 conseguiram realizar o objetivo proposto.

\section{Resultados e Discussão}

Os podcasts produzidos pelos estudantes não foram avaliados numericamente. Porém, para este trabalho, os resultados foram relacionados com a abordagem BYOD e o desenvolvimento da competência de leitura em língua inglesa, além de habilidades do $\mathrm{RC}$, ainda que não tenha sido o foco da intervenção. $\mathrm{O}$ quantitativo de podcasts produzidos pode ser consultado na Tabela 1 .

A Tabela 1 mostra o quantitativo de podcasts produzidos pelos estudantes. A coluna dos verbos terminados com o som /id/, há 07 podcasts, na qual destacam-se os número 04 e 11, cujos estudantes produziram a quantidade de 09 e 10 verbos. O podcast 09 foi produzido por uma dupla de estudantes. As orientações foram para produções individuais, contudo, perceber-se que a produção em dupla é uma oportunidade para desenvolver a autoconfiança e a autoestima.

A segunda coluna, cujos verbos possuem o som $/ \mathrm{t} /$, houve a produção de cinco podcasts. Destaque para os podcasts 01 com a gravação de 10 verbos e o de número 03

\footnotetext{
3 Bluetooth é uma rede sem fio de âmbito pessoal e provê uma maneira de conectar e trocar informações entre dispositivos como telefones celulares, notebooks, computadores, impressoras, câmeras digitais, etc.
} 
com a gravação de 13 verbos. Na coluna com os verbos de som /d/, destaca-se o podcast de número 13 , cujo autor conseguiu gravar 12 verbos.

Tabela 1 - Quantitativo de podcasts produzidos pelos estudantes

\begin{tabular}{|c|c|c|c|}
\hline Podcasts & /id/ & /t/ & $/ \mathbf{d} /$ \\
\hline 01 & & 10 verbos & \\
\hline 02 & & 05 verbos & \\
\hline 03 & & 13 verbos & \\
\hline 04 & 09 verbos & & \\
\hline 05 & & 10 verbos & \\
\hline 06 & 01 verbo & & \\
\hline 07 & 01 verbo & & \\
\hline 08 & 03 verbos & & \\
\hline $09-$ dupla & 06 verbos & & \\
\hline 10 & & & 03 verbos \\
\hline 11 & 10 verbos & & \\
\hline 12 & & & 03 verbos \\
\hline 13 & & & 12 verbos \\
\hline 14 & & & 03 verbos \\
\hline 15 & & 02 verbos & \\
\hline 16 & & & 02 verbos \\
\hline 17 & 03 verbos & & \\
\hline
\end{tabular}

A pronúncia de alguns verbos não foi adequada, porém foi possível reconhecer qual verbo o autor do podcast estava mencionando. Entretanto, na maioria dos podcasts, os estudantes conseguiram gravar os verbos com uma pronúncia adequada e pôde-se compreender nitidamente o verbo pronunciado.

Para corroborar com os resultados desta seção, perguntou-se nas entrevistas, se a atividade com o uso do celular contribuiu para a aprendizagem dos conteúdos. Os estudantes relataram que contribuiu para aprender os sons dos verbos no tempo passado, além de proporcionar uma oportunidade para falar em inglês. Percebe-se que os estudantes sentem vontade de aprender a falar inglês e, a partir dessa atividade, observaram que não é simples desenvolver a habilidade speaking (fala), porém é possível com dedicação e técnicas adequadas. Guaresi e Webber (2017) propõem o uso

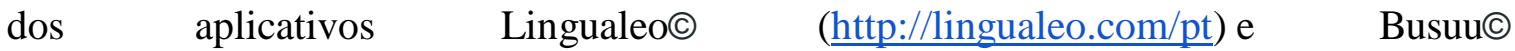
(https://www.busuu.com/pt) para a habilidade speaking.

A partir das entrevistas, elencamos algumas respostas dos alunos em que podemos perceber que a atividade com o podcast, contribuiu no processo de aprendizagem. Vejamos: "foi uma atividade prática"; "boa oportunidade de praticar o inglês"; "foi bom usar o celular para aprender inglês"; "consegui interpretar os verbos no passado"; "ouvir o som dos verbos e a minha voz, ajudou bastante”; "uma atividade divertida".

Percebeu-se que os estudantes desejam atividades práticas, o uso do celular e da abordagem BYOD podem proporcionar isso. O uso do celular pode despertar o interesse dos estudantes durante as atividades em sala de aula e, segundo Demo (2011) cabe ao professor conduzir o desenvolvimento da aprendizagem cognitiva. Dentre as frases destacadas nas falas dos estudantes, ressaltou-se "ouvir o som e a voz". Durante a atividade, ao ouvirem suas próprias vozes, sentiram-se alegres porque falaram inglês. Uma estudante, ao ouvir a sua própria voz verbalizando uma palavra em inglês, após a 
reprodução do áudio, gritou “- Professor! Aqui, professor! Consegui! (risos). Eu consegui, professor! Eu falei inglês.”. Segundo Godoy (2006), quando o professor vai planejar alguma atividade envolto da habilidade speaking, deve responder às seguintes questões: por que falar; o que falar; e como falar.

Outra frase verbalizada pelos estudantes que nos chamou a atenção foi “(...) uma atividade divertida", destacando a ludicidade integrada às aulas. Nogueira (2008, p. 04) nos lembra que "a ludicidade deve ser usada como um recurso pedagógico, (...) integra as várias dimensões da personalidade: afetiva, motora e cognitiva". Por esse ponto de vista, inferiu-se que a atividade com o uso e produção de podcast foi uma atividade lúdica.

Alguns estudantes sentiram dificuldade em ouvir e produzir os áudios. O que fora relatado em alguns momentos, tangenciado as dificuldades em utilizar o celular na atividade de uso e produção de podcast, como em: "até facilita a aprendizagem, ajuda na pronúncia correta dos verbos", "não é obrigado saber pronunciar corretamente os verbos"; "foi difícil"; "não conhecemos muitas palavras em inglês"; "para os estudantes tímidos, falar inglês não é legal porque todo mundo vai ouvir”.

Quando os estudantes sentem dificuldades em realizar uma tarefa proposta pelo professor na aula de inglês, pode haver a sensação de dificuldade. Isso ocorreu nessa experiência. Segundo Montrezor e Silva (2009) os estudantes consideram a língua inglesa difícil porque a estrutura e a origem dessa língua são diferentes da nossa língua materna, os aspectos culturais e sociais também são diferentes.

Destacamos também a percepção da professora. Vejamos o relato dela sobre o uso do celular e do podcast em sala de aula:

\begin{abstract}
A atividade contribuiu para o desenvolvimento deles em sala de aula, (...) perder a inibição em sala de aula (...) é um recurso que pode ser utilizado porque ao invés de apresentar, você pode gravar a sua própria voz e, assim com o tempo, ele vão se desenvolvendo, perdendo a timidez (...). Bem, achei ótimo o trabalho (...), pois eles não têm esse costume (de ouvir inglês), (...) e também deles ouvirem a própria pronúncia, porque eles estão acostumados mais somente a ouvir pouco porque eu utilizo pouco o áudio, mas tem muitos alunos que assistem muitas séries então eu acredito que até o desenvolvimento deles, de alguns deve ter tido êxito devido a isso, (...) porque tem muitos que gostam de assistir séries em inglês, ouvir músicas, então, pode ser que uns tenham tido mais facilidades por isso, por escutar, agora muito interessante eles produzir o áudio e se ouvirem porque deixa de ficar somente recebendo, então, produzir é muito interessante para eles verem o progresso deles, acompanharem. (A professora)
\end{abstract}

Por essa e outras falas da professora na entrevista pós intervenção foi possível perceber que para ela, a intervenção favoreceu (em algum modo) tanto o ensino quanto a aprendizagem. A professora destaca que a técnica pode ser utilizada para os estudantes gravarem, por exemplo, suas apresentações. Ela ressaltou que podcasts podem ser utilizados em sala de aula, sem grandes complicações; porém, é adequado realizar um planejamento cuidadoso considerando as características da turma e da escola.

Em relação às habilidades do $\mathrm{RC}$, o ato da observação e o estudo das regras do simple past podem contribuir ao desenvolvimento da habilidade reconhecimento de padrões. O padrão estabelecido para a língua inglesa pode ser utilizado em qualquer contexto e em diversas tipologias textuais. Nesse sentido, Csizmadia et al. (2015) destacam que o reconhecimento de padrões é perceber a similaridade, conexões e 
características de um determinado problema, assim, ao perceberem a similaridade dos verbos no tempo passado, puderam conectar com a temática cantores de hip-hop.

A habilidade de abstração está implícita no processo de ouvir e produzir o podcast. Os estudantes ouviam o áudio, uma coluna por vez. Focalizavam nos verbos da primeira coluna, mantinham a atenção nos verbos terminados em /id/, não se preocupam com os verbos da segunda e da terceira coluna. Assim, podemos compreender que o processo de abstração foi desenvolvido durante a atividade de ouvir os sons dos verbos.

O modo como cada estudante desenvolveu o seu podcast é um detalhe no processo de abstração. A produção foi diferente, pois usaram estratégias distintas na tentativa de compreender os sons dos verbos e resolver o problema proposto. O aparelho celular contribuiu para a atividade, pois segundo Geddes (2004) a aprendizagem móvel coopera na construção de conhecimentos e habilidades, no momento em que as pessoas estão usando equipamentos tecnológicos móveis, a qualquer hora e em qualquer lugar, sendo que as pessoas tenham objetivos em função da construção do conhecimento e habilidades.

Portanto, a partir das inferências realizadas por meio das respostas às entrevistas, foi possível perceber que a intervenção contribuiu para o desenvolvimento da competência Ler e interpretar textos de diversas naturezas. Entretanto, não é cabível mensurar o nível de desenvolvimento da competência de língua inglesa. O que se pode fazer é inferir por meio da correção da atividade (não destacada neste artigo) que a competência foi desenvolvida de modo intrínseco.

\section{Considerações finais}

Ao final da intervenção, restaram algumas reflexões e observações acerca do desenvolvimento dos estudantes no âmbito da aprendizagem de língua inglesa. Por exemplo, o professor pode:

- planejar atividades com o objetivo de permitir que os estudantes compreendam e aprendam adequadamente o conteúdo curricular, atenuando alguns problemas do seu cotidiano de sala de aula;

- buscar estratégias para ensinar os conteúdos, por meio de recursos didáticos e tecnológicos que sejam intermediadores da aprendizagem e estejam disponíveis aos estudantes;

- utilizar das tecnologias que os estudantes carregam consigo para fazer uso de metodologias mais dinâmicas;

- estimular o uso e produção de podcast e da abordagem BYOD para possibilitar uma aprendizagem significativa.

Para a comunidade escolar utilizar a abordagem BYOD, é importante que haja planejamento pedagógico flexível, com ampla discussão com os membros do corpo escolar e, preferencialmente, haja indicação explícita dessa abordagem em seu Projeto Político-Pedagógico (PPP).

Nessa experiência percebemos algumas vantagens, mas também algumas desvantagens no uso dos podcasts na abordagem BYOD. Por exemplo, a timidez e a vergonha de falar inglês ocasionaram a falta de produção de podcasts de alguns estudantes; outros relataram que não precisam aprender a falar inglês. Apesar dessas situações, sempre que o professor for utilizar tecnologias em sala de aula é importante verificar quais recursos disponíveis com os estudantes e com a comunidade escolar.

Portanto, parece conveniente afirmar que uma abordagem didática baseada no BYOD poderá trazer resultados positivos à aprendizagem e nas práticas pedagógicas dos professores e do corpo escolar. 
O uso dos aparelhos celulares em sala de aula requer cuidados, porque muitos estudantes talvez ainda não possuem maturidade em utilizar os recursos tecnológicos móveis em função da própria aprendizagem. A facilidade para dispersão nas aulas é uma fator existente, ao invés de contribuírem poderão atrapalhar o processo de ensino aprendizagem. Parece que quanto mais familiarizados os estudantes estiverem com o recurso que o professor deseja usar, certamente os objetivos das aulas poderão ser alcançados com maior êxito.

\section{Referências}

AARRENIEMI-JOKIPELTO, P.; GOULART, E. Localised mobile learning solutions: Responding to the needs of global education. VI Congresso Brasileiro de Informática na Educação (CBIE) In: Anais do XXVIII Simpósio Brasileiro de Informática na Educação (SBIE), p. 374-383. 2017.

ALBERTA, E. Bring your own device: a guide for schools. School Technology Brach. Alberta, Canadá. 2012. Disponível em: 〈http://education.alberta.ca/admin/technology/research.aspx > Acesso em: 15 jan. 2018.

BARCELOS, R.; TAROUCO, L.; BERCHT, M. O uso de mobile learning no ensino de algoritmos. RENOTE, v. 7, n. 3, p. 327-337. 2009.

BOTTENTUIT JUNIOR, J. B.; COUTINHO, C. M. P. Blog e Wiki: os futuros professores e as ferramentas da Web 2.0. In: Anais do IX Simpósio Internacional de Informática Educativa. p. 199-204. 2007.

BRASIL, Ministério da Educação. Secretaria da Educação Básica. Pcn+ ensino médio: Orientações educacionais complementares aos parâmetros curriculares nacionais, Brasília: MEC. 2002.

DIAS, R.; JUCÁ, L.; FARIA, R. High Up: ensino médio. Cotia, SP: Macmillan. 2013.

COSTA, A. C., FRANCO, A. A.; MOTA, C. V. A.; JULliAN, R.; GADELHA, R. L. L. M-learning: Celulares utilizados como ferramenta didática numa escola pública de Ensino Médio. In: Anais do XXII Workshop de Informática na Escola, p. 575-582. 2016.

CSIZMADIA, A.; CURZON, P.; DORLING, M.; HUMPHREYS, S.; NG, T.; SWLBY, C.; WOOLLARD, J. Computational thinking - A guide for teachers. Computing At School. $2015 . \quad$ Disponível em: https://community.computingatschool.org.uk/files/8550/original.pdf>. Acesso em: 26 out. 2018.

DEMO, P. Educar pela pesquisa. 7. ed. Campinas: Autores Associados. 2011. BOTTON, L.A.; PERIPOLLI, P. Z.; SANTOS, L. M. A. Podcast-uma ferramenta sob a ótica dos recursos educacionais abertos: apoio ao conhecimento. Redin-Revista Educacional Interdisciplinar, v. 6, n. 1, 2017.

DOS REIS, S. C.; AVILA, L. D. A. B.; VARGAS, R. D. B. Iniciação científica em Letras com alunos da escola pública: letramento digital e produção de podcasts em língua inglesa no ensino fundamental. RENOTE, v. 12, n. 2, p.1-10. 2014.

DUTRA, A.; DOS SANTOS, C. P.; Dos Santos, G. J. F.; BELl'AVER, J. E. M.; IDALGO, L. O Podcast no Ensino de Inglês: Contribuição para a Prática Oral de Estudantes do Ensino Médio. Revista de Ensino, Educação e Ciências Humanas, v. 17, n. 5, p. 426-431. 2016. 
FIGUEIREDO, M. A.; SILVA, O. G.; COSTA, S. R.. Programas de Nivelamento de Matemática e Português: M-Learning com Videoaulas, In: Anais do $\mathbf{1 7}^{\mathbf{0}}$ Congresso Internacional de Educação a Distância. Manaus. [s.p]. 2011. Disponivel em: 〈http://www.abed.org.br/congresso2011/cd/42.pdf>. Acesso em: 20 jan. 2018.

GEDDES, S. J. Mobile learning in the 21st century: benefit for learners. Knowledge Tree e-journal, v. 30, n. 3, p. 214-228. 2004.

GODOY, S. M. B.; GONTOW, C.; MARCELLINO, M. English pronunciation for brazilians: the sounds of American English. São Paulo, Barueri: Disal. 2006.

GUARESI, G.; WEBBER, C. G. Softwares para desenvolvimento de habilidades em Língua Inglesa. Scientia cum Industria, v. 5, n. 2, p. 108-120. 2017.

INSIGHT, A. A. S. The 2014-2019 Brazil mobile learning market. Ambient Insight's $2015 . \quad$ Disponível em: <http://www.ambientinsight.com/Resources/Documents/AmbientInsight-2014-2019-Br azil-Mobile-Learning-Market-Abstract.pdf>. Acesso em: 20 jan. 2018.

MARÇAL, E.; ANDRADE, R.; VIANA, W.; JUNQUEIRA, E.; MELO. R. Análise do uso de mensagens de celular na melhoria da participação de estudantes em cursos a distância: um estudo de caso. RENOTE, v. 14, n. 2, p.1-10. 2016.

MONTREZOR, B. M.; SILVA, A. B. A dificuldade no aprendizado da Língua Inglesa The difficulty in English Language Learning. Cadernos UniFOA, v. 4, n. 10, p. 27-32, 2017.

NOGUEIRA, Z. P. Atividades lúdicas no ensino/aprendizagem de língua inglesa. Portal Dia-a-dia Educação. 2008.2 Disponível em: 〈http://www.diaadiaeducacao.pr.gov.br/portals/pde/arquivos/967-4.pdf $>$. Acesso em 20 jan. 2018.

PHILLIPS, B. Empowering students: Using technology-enhanced learning to foster learner autonomy. In: Pannonia Research Award, p. 83-94. 2015. Disponível em: http://hdl.handle.net/20.500.11790/57. Acesso em: 20 jan. 2018.

PHILLIPS, B. Student-Produced Podcasts in Language Learning--Exploring Student Perceptions of Podcast Activities. IAFOR Journal of Education, v. 5, n. 3, p. 157-171. 2017.

PRENSKY, M.. Digital natives, digital immigrants part 1. On the horizon, v. 9, n. 5, p. $1-6,2001$.

PRIMO, A. F. T. Para além da emissão sonora: as interações no podcasting. Intexto: revista do mestrado da comunicação UFRGS. v. 2, n. 12, jul./dez, p. 1-23, 2005.

SHULER, C.; WINTERS, N.; SHARPLES, M.; VOSLOO, S.; WEST, M. UNESCO/Nokia The Future of Mobile Learning Report: Implications for Policymakers and Planners. 2013. Disponível em: http://discovery.ucl.ac.uk/id/eprint/10016465. Acesso em: 22 jan. 2018.

SILVA, A.; DUQUE, L. V.; SILVA, S. P. O uso de podcasts no desenvolvimento da oralidade em língua inglesa. Pesquisas em Discurso Pedagógico, v. 2, n. 12, p. 21-23. 2012.

SILVA, M. S. Dificuldades do ensino na oralidade em aulas de língua inglesa. Revista Fronteira Digital, n. 4, ano II, ago/dez, p. 92-99. 2011. 
THEODORIDIS, S.; KOUTROUMBAS, K. Pattern recognition. IEEE Transactions on Neural Networks, v. 19, n. 2, p. 376-376. 2008.

WING, J. M. Computational thinking. Communications of the ACM, v. 49, n. 3, p. 33-35. 2006.

XAVIER, M. C. F.; DIAS, L. R. Pelo telefone-histórias e relatos sobre o uso de celulares como ferramenta de ensino e aprendizagem de língua inglesa no Brasil. Congresso Brasileiro de Informática na Educação. In: Anais do XVIII Workshop de Informática na Escola (WIE), p. 1-10, 2012. 